This document is the Accepted Manuscript version of a Published Work that appeared in final form in Langmuir copyright $($ ) American Chemical Society after peer review and technical editing by publisher. To access the final edited and published work see Zhang, X., Servos, M. R., \& Liu, J. (2012). Surface Science of DNA Adsorption onto Citrate-Capped Gold Nanoparticles. Langmuir, 28(8), 3896-3902. https://doi.org/10.1021/la205036p

\title{
The Surface Science of DNA Adsorption onto Citrate-Capped Gold
}

\section{Nanoparticles}

\author{
Xu Zhang ${ }^{\dagger \dagger}$, Mark R. Servos ${ }^{\ddagger}$ and Juewen Liu ${ }^{\dagger *}$ \\ $\dagger$ \\ Departments of Chemistry and Waterloo Institute for Nanotechnology, Department of Biology \\ University Of Waterloo, Waterloo, Ontario, N2L 3G1, Canada \\ Email: liujw@uwaterloo.ca
}

\begin{abstract}
Single-stranded DNA can be adsorbed by citrate capped gold nanoparticles (AuNPs), resulting in increased AuNP stability, which forms the basis of a number of biochemical and analytical applications, but the fundamental interaction of this adsorption reaction remains unclear. In this study, we measured DNA adsorption kinetics, capacity, and isotherms, demonstrating that the adsorption process is governed by electrostatic forces. The charge repulsion among DNA strands and between DNA and AuNPs can be reduced by adding salt, reducing $\mathrm{pH}$ or by using non-charged peptide nucleic acid (PNA). Langmuir adsorption isotherms are obtained, indicating the presence of both adsorption and desorption of DNA from AuNPs. While increasing salt concentration facilitates DNA adsorption, the desorption rate is also enhanced in higher salt due to DNA compaction. DNA adsorption capacity is determined by both DNA oligomer length, DNA concentration and salt. Previous studies indicated faster adsorption of short DNA oligomers by AuNPs, we find that once adsorbed, longer DNAs are much more effective in protecting AuNPs from aggregation. DNA adsorption is also facilitated by using low pH buffers and high alcohol concentrations. A model based on electrostatic repulsion on
\end{abstract}


AuNPs is proposed to rationalize the aforementioned DNA adsorption/desorption behavior. 


\section{Introduction}

Gold nanoparticles (AuNPs) play a particularly important role in bionanotechnology because they are ideal for interfacing with biomolecules and cells. ${ }^{1-6}$ AuNPs are available in large quantities with excellent size and shape control. At the same time, they are non-toxic, stable, conductive, catalytically active, and electron dense. ${ }^{7}$ AuNPs possess unique optical properties in terms of extremely high extinction coefficients, distance-dependent color and outstanding fluorescence quenching ability, popularizing them for biosensor development. Finally, thiol-containing biopolymers can chemisorb onto AuNPs to give rise to both colloidal stability and functionalization. Proteins and nucleic acids 36 without thiol groups can also be adsorbed via other interactions. Many of these properties have been known for a long time and AuNPs were prepared over 150 years ago, but the role of AuNPs in bionanotechnology emerged only since 1996 when thiol-modified DNAs were used to functionalize AuNPs. ${ }^{8,9}$ The programmable nature of DNA has been passed to 40 AuNPs, making it possible to synthesize AuNP oligomers, ${ }^{9,} 10$ random aggregates, ${ }^{8}$ periodic structures $^{11,} 12$ and crystalline superlattices.13-15 While most studies involved thiolated DNA,16-21 adsorption of non-thiolated DNA has also turned out to be quite useful. ${ }^{22-24}$ For example, adsorption of short single43 stranded (ss)-DNA is much faster than that for long, double-stranded (ds) or other well-folded DNAs. Therefore, AuNPs have been used as a probe for DNA secondary structure and related analytical applications. ${ }^{25-32}$ DNA adsorption has also been used to control the growth of AuNPs, ${ }^{33,34}$ tune catalytic activities of AuNPs, ${ }^{35}$, ${ }^{36}$ and improve the specificity of polymerase chain reactions (PCR). ${ }^{37} 47$ Finally, applications related to drug delivery can also be envisioned. ${ }^{33,38}$ Given all these reported applications, the mechanism of nonthiolated DNA adsorption remains a controversy. The most commonly used $\sim 13 \mathrm{~nm}$ AuNPs are capped by negatively charged citrate, posing an electrostatic barrier for adsorbing negatively charged DNA. Therefore, DNA adsorption must be achieved by non-ionic forces. It has been observed that different 
DNA bases show different binding affinity, highlighting the importance of specific nucleobase-Au interaction. ${ }^{27,39-43} \mathrm{Li}$ and Rothberg initially used the DLVO (Derjaguin, Landau, Verwey and Overbeek) theory to describe the adsorption of ss-DNA onto AuNPs. ${ }^{23}$ Recently, Nelson and Rothberg proposed that hydrophobic interactions should be the main attractive force, since the previously cited DLVO theory could not account for the difference between the adsorption of ss- and ds-DNA, the adsorption of different DNA base sequences, or the effect caused by different types of inorganic salts. ${ }^{41}$ However, this viewpoint is not in line with the observation that the surface of freshly prepared AuNPs is hydrophilic. ${ }^{44,45}$ Other studies indicated specific bonding interaction between DNA bases and AuNPs. ${ }^{42}$, ${ }^{46-49}$ In addition, the belief that DNA adsorption is irreversible or desorption does not occur has not been substantiated with experimental evidence. ${ }^{23}$ Finally, it was observed that shorter DNA strands are adsorbed more quickly than longer ones, but their relative effectiveness in protecting AuNPs from saltinduced aggregation might follow a different trend, since it is quite straightforward to assume that the longer DNAs bind more tightly to AuNPs due to the establishment of more contacting points on AuNP surface.

These inconsistencies in the literature reflect the lack of a complete understanding of the fundamental adsorption mechanism between DNA and AuNPs, which hinders the further development of materials and devices exploiting these interactions. In this work, by measuring a number of important surface science parameters including adsorption kinetics, adsorption isotherm and capacity as a function of DNA length, charge, $\mathrm{pH}$, salt concentration and solvent polarity, we provide new evidence to resolve the above controversies and offer new insights to the mechanism of DNA adsorption on AuNPs. 


\section{Materials and Methods}

Chemicals. All the DNA samples were purchased from Integrated DNA Technologies (Coralville, IA) and were purified by standard desalting. The peptide nucleic acid (PNA) was purchased from Biosynthesis Inc. (Lewisville, TX) and dissolved in $0.1 \%$ trifluoroacetic acid. The DNA and PNA sequences are shown in Table 1 and none of them can form stable secondary structures as predicted by Mfold (folded in $50 \mathrm{mM} \mathrm{NaCl}$ at 25 पC). ${ }^{50} \mathrm{HAuCl}_{4}$ and $\square$-mercaptoethanol (BME) were from SigmaAldrich. AuNPs were synthesized based on the standard citrate reduction procedures and its concentration was estimated to be $\sim 10 \mathrm{nM} .{ }^{51}$ Ethanol, sodium hydroxide, and hydrochloric acid were purchased from VWR (Mississauga, ON). Sodium citrate, sodium chloride and 4-(2-hydroxyethyl) piperazine-1-ethanesulfonate (HEPES) were purchased from Mandel Scientific (Guelph, ON). MilliQ water was used for all experiments.

DNA or PNA adsorption. To study the DNA adsorption kinetics, 1 nM FAM-DNA (FAM = 6carboxyfluorescein; 12-mer, 24-mer, or 44-mer) was dissolved in $90 \mu \mathrm{L}$ of HEPES buffer (5 mM, pH 7.6) containing various concentrations of $\mathrm{NaCl}(0,10,30,60,90 \mathrm{mM})$. The fluorescence intensity at $520 \mathrm{~nm}$ was monitored for 1 min under the kinetic mode using a plate reader (Tecan Infinite F200Pro) prior to a quick addition and mixing with $10 \mu \mathrm{L}$ of $10 \mathrm{nM}$ AuNPs (final AuNP concentration $=1 \mathrm{nM}$ ). The adsorption kinetics of PNA to AuNPs was obtained in a similar way, and the initial PNA concentration was $7 \mathrm{nM}$. To obtain DNA adsorption isotherm, the DNA and AuNP mixtures with various concentrations of $\mathrm{NaCl}$ were kept in $1.5 \mathrm{~mL}$ microcentrifuge tubes overnight at room temperature. The amount of adsorbed DNA on the AuNP surface was determined by fluorescence measurement after spinning down the AuNPs (10 min, $15000 \mathrm{RMP})$ and releasing the DNA with $1 \mu \mathrm{L}$ of $1 \mathrm{M}$ BME. The supernatant fluorescence was also measured so that the percentage of adsorption can be calculated. 
pH and ethanol effect. The same procedure was applied to investigate the adsorption of DNA onto AuNPs with different concentrations of ethanol or $\mathrm{pH}$. To adjust $\mathrm{pH}, 2 \mu \mathrm{L}$ of $\mathrm{HCl}(100 \mathrm{mM}$ for $\mathrm{pH} 3.5)$, acetate (500 mM, pH 4 and 5), MES (500 mM, pH 6.1), and HEPES (500 mM, pH 7.6) were added into a mixture containing $5 \mathrm{nM}$ AuNPs, $100 \mathrm{nM}$ 12-mer DNA with a total volume of $100 \mu \mathrm{L}$. The incubation time was $5 \mathrm{~min}$ at room temperature.

DNA desorption. To study DNA desorption kinetics, AuNPs with adsorbed DNA were first prepared by incubating $500 \mu \mathrm{L}$ of $5 \mathrm{nM}$ AuNPs with $100 \mathrm{nM}$ FAM-labeled DNA and $30 \mathrm{mM} \mathrm{NaCl}$ at room temperature overnight. The free DNAs were removed by 3 rounds of centrifugation and re-suspension with $5 \mathrm{mM}$ HEPES buffer. The final conjugate was dispersed in $100 \mu \mathrm{L}$ of $5 \mathrm{mM}$ HEPES buffer. Five microliters of the DNA-AuNP conjugate was added into $95 \mu \mathrm{L}$ HEPES buffer containing varying concentrations of $\mathrm{NaCl}$ and the kinetics of fluorescence change was monitored.

Gel electrophoresis. The DNA-AuNP conjugates were prepared by incubating $5 \mathrm{nM}$ AuNPs with 100 nM DNA for $30 \mathrm{~min}$. The gel was prepared to contain $1 \%$ agarose and $10 \mathrm{mM}$ HEPES, pH 7.6. Thirty microliters of DNA-AuNP conjugates containing 25\% glycerol was added to each lane and the gel was run at $70 \mathrm{~V}$. The running buffer also contained only $10 \mathrm{mM}$ HEPES. The AuNP bands were recorded with a digital camera (Canon Powershot SD1200 IS).

Table 1. DNA and PNA sequences and modifications used in this work.

Name Sequence and modifications (from $5 \square$ to 3ロ)

12-mer FAM-CACTGACCTGGG

24-mer FAM-ACGCATCTGTGAAGAGAACCTGGG 


\section{Results and discussion}

Effect of salt concentration on DNA adsorption kinetics. Since both citrate capped AuNPs and DNA are negatively charged, DNA adsorption is affected by the long-range electrostatic repulsion, whose range is related to the salt-dependent Debye length $\left(\square_{D}\right)$. Only when a DNA is sufficiently close to the AuNP surface can short-range attractive forces take place to achieve adsorption. While different types of inorganic salts have been tested, ${ }^{41}$ we reason that studying the effect of salt concentration can provide quantitative information regarding the adsorption mechanism. Taking advantage of the observation that fluorescence is quenched in proximity of AuNPs, we employed a FAM-labeled 12-mer DNA and monitored its fluorescence upon mixing with AuNPs. The normalized kinetic traces of fluorescence change are shown in Figure 1A and the procedures for normalization are described in Supporting Information. DNA adsorption occurs very slowly in the absence of additional salt (e.g. fluorescence drop $<10 \%$ in $10 \mathrm{~min}$ ). Adsorption becomes progressively faster in higher salt concentrations. With >60 $\mathrm{mM} \mathrm{NaCl}$, for example, adsorption is close to completion in just $1 \mathrm{~min}$.

This data quantitatively describe the role of salt in affecting DNA adsorption. Initially, the AuNPs were stabilized by citrate. If no additional $\mathrm{NaCl}$ was added, the lowest salt sample contained $4 \mathrm{mM} \mathrm{Na}^{+}$from the HEPES buffer and sodium citrate in the AuNP solution. The highest salt 
concentration we tested was only $90 \mathrm{mM} \mathrm{NaCl}$, which already started to cause aggregation of AuNPs. Therefore, higher salt concentrations were not tested. From $4 \mathrm{mM}$ to $90 \mathrm{mM} \mathrm{NaCl}, \square_{D}$ decreases from $4.7 \mathrm{~nm}$ to $1 \mathrm{~nm}$. Fast adsorption started to occur with higher than $30 \mathrm{mM} \mathrm{NaCl}$, where $\square_{D}=1.7 \mathrm{~nm}$. Therefore, we estimate that attractive forces start to take place in this range.
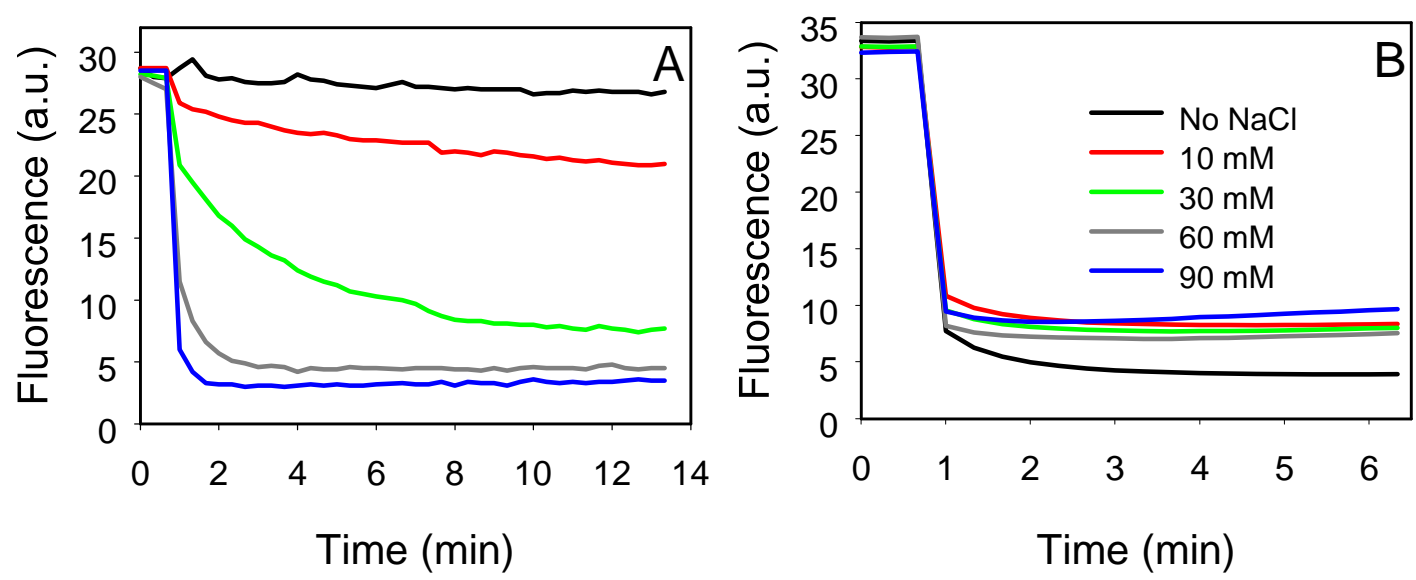

Figure 1. The adsorption kinetics of FAM-labeled 12-mer DNA (A) and PNA (B) on AuNPs in 5 mM HEPES buffer ( $\mathrm{pH}$ 7.6) containing various concentrations of $\mathrm{NaCl}$. DNA or PNA was added at $\sim 1 \mathrm{~min}$.

Adsorption of PNA. To further understand the effect of salt and charge on DNA adsorption, a noncharged DNA analog, peptide nucleic acid (PNA) with the same sequence was also tested. Due to the absence of negative charges, PNA has been previously shown to induce AuNP aggregation. ${ }^{52}$ In this case, we observed that the adsorption kinetics were independent of salt concentration (Figure 1B). Adsorption was finished in $\sim 20 \mathrm{sec}$ for all the tested conditions, which was much faster compared to that for DNA adsorption. This experiment indicates that the adsorption energy barrier is much lower for the PNA, further confirming the main contribution of electrostatic repulsion between DNA and AuNPs. Effect of salt on DNA adsorption capacity. The above kinetic experiments monitored DNA adsorption 
for only $\sim 10 \mathrm{~min}$. The effect of salt concentration and DNA length was tested after an overnight incubation to reach binding equilibrium. The $y$-axis of Figure $2 \mathrm{~A}$ indicates the average number of adsorbed DNA molecules on each AuNP. More DNAs are adsorbed in the presence of more salt, and this is true for all the three DNA lengths. Therefore, salt affects not only the adsorption kinetics, but also the final adsorption capacity. For the 12-mer DNA, the adsorption capacity stops increasing if $\mathrm{NaCl}$ is higher than $60 \mathrm{mM}$. Under such conditions, each AuNP adsorbs around fifteen 12mer DNAs.

The adsorption capacity is also a function of DNA length. With the same salt concentration, more short DNAs were adsorbed. It is interesting to compare the adsorption capacity of non-thiolated and thiolated DNA. In the latter case, around one hundred 12-mer DNAs can be immobilized on each $13 \mathrm{~nm}$ AuNPs. ${ }^{53-55}$ This high capacity is related to the single thiol anchor versus the presence of multiple contacting points for non-thiolated DNAs (i.e. non-thiolated DNA may wrap AuNPs).
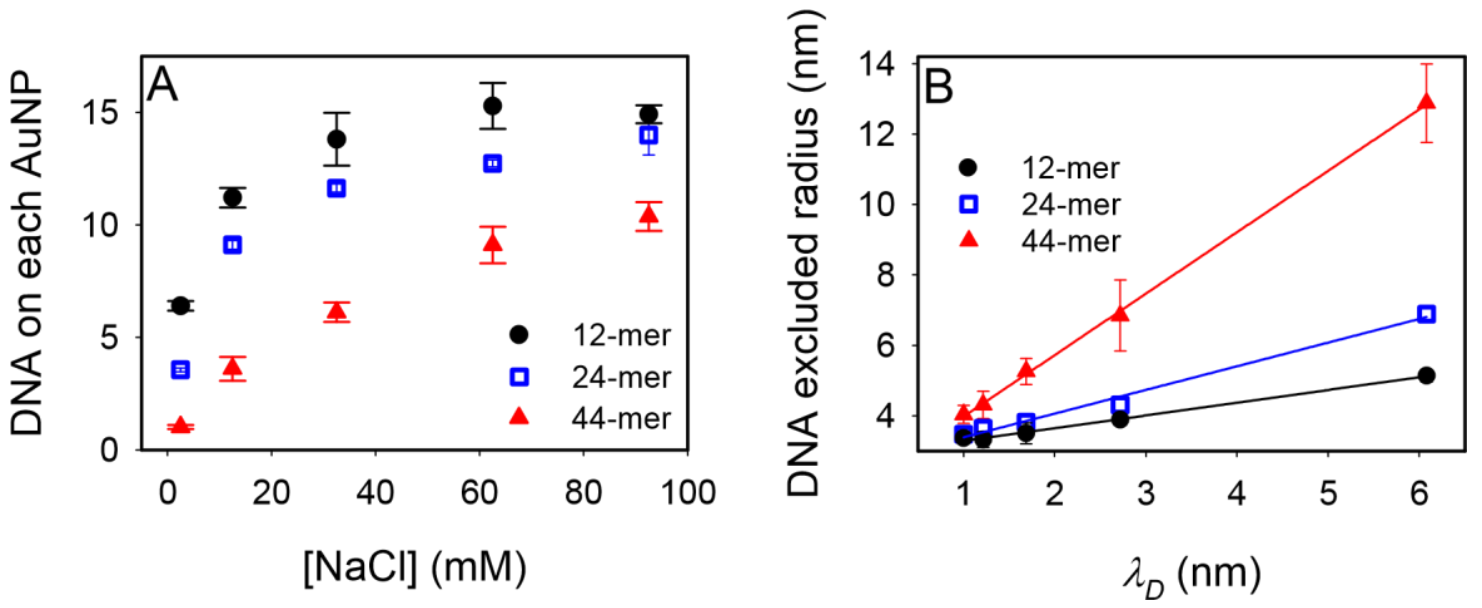

Figure 2. (A) DNA adsorption capacity of AuNPs as a function of $\mathrm{NaCl}$ concentration. Three DNA lengths were tested. (B) The linear relation between the DNA excluded radius and Debye length $\left(\square_{D}\right)$ under various $\mathrm{NaCl}$ concentrations. 
To further understand the binding between DNA and AuNPs, samples incubated in different salt concentrations were analyzed using agarose gel electrophoresis. ${ }^{56}$ To minimize AuNP aggregation, the running buffer contained only $10 \mathrm{mM}$ HEPES ( $\mathrm{pH}$ 7.6) and the gels were also made using the same buffer. The AuNP in all the samples were dispersed as indicated by a red color before running the gel (Figure 3A). After running, AuNPs with thiol-modified DNA migrated as a single band with the highest speed (Figure 3B, lane 1). Citrate capped AuNPs without any DNA barely migrated before they started to aggregate, accompanying the AuNP color changing to blue (lane 2). AuNPs with the 12-mer nonthiolated DNA (lanes 3-6) migrated faster than the citrate capped ones indicating that adsorbed DNA increased the number of negative charges on the AuNPs. AuNPs incubated in higher salt concentrations migrated to a greater distance. Combined with the adsorption capacity data (Figure 2A), we conclude that more DNAs are adsorbed in higher salt buffers to provide more negative charges on AuNPs and faster migration on gel. The electrophoretic motion stopped once all the AuNPs changed color to blue. This color change also suggests that at least a fraction of adsorbed DNA and citrate are desorbed by the electric field, making the AuNPs less protected.

It appears that the best way to adsorb a large number of DNA onto AuNPs without causing its aggregation is to add $\mathrm{NaCl}$ in a stepwise manner. $\mathrm{As} \mathrm{NaCl}$ is gradually added, more DNA can be adsorbed to allow AuNPs to withstand an even higher $\mathrm{NaCl}$ concentration. This technique has been used to achieve a high DNA density for thiolated DNA. ${ }^{53,55}$ To test it for non-thiolated DNA, we incubated $5 \mathrm{nM}$ AuNPs with $100 \mathrm{nM}$ DNA for $30 \mathrm{~min}$ before adding $\mathrm{NaCl}$ to the mixture. In one sample, $120 \mathrm{mM} \mathrm{NaCl}$ was added all at once resulting in a color change to purple indicating aggregation of the AuNPs (Figure 3E, tube 2). In another tube $\mathrm{NaCl}$ was added in increments of $30 \mathrm{mM}$, $60 \mathrm{mM}$ and $60 \mathrm{mM}$ over $1 \mathrm{hr}$ (final $\mathrm{NaCl}=150 \mathrm{mM}$ ) and the color of AuNPs remained red (tube 3). 
The control tube with no DNA showed a blue color (tube 1).

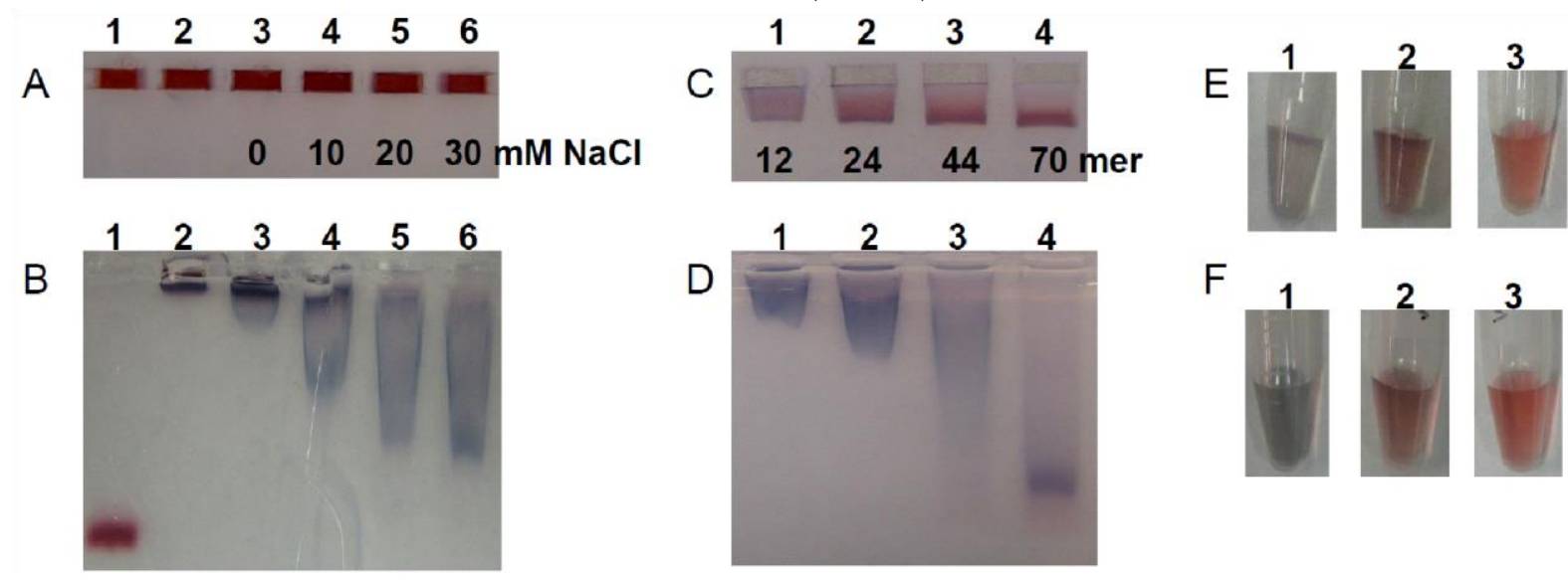

Figure 3. Agarose gel electrophoresis of DNA/AuNP conjugates. Salt-dependent study before (A) and after (B) gel running. Lane 1: thiol-DNA functionalized AuNPs. Lane 2: bare citrate capped AuNPs without DNA or NaCl. Lanes 3-6, AuNPs incubated with the 12-mer DNA in 5 mM HEPES buffer with various $\mathrm{NaCl}$ concentrations. The effect of DNA length demonstrated after running the gel for $10 \mathrm{~min}$ (C) and $1 \mathrm{hr}$ (D). (E) The effect of step-wise salt addition. Tube 1: no DNA, $90 \mathrm{mM} \mathrm{NaCl}$. Tube 2: 100 nM DNA, and $120 \mathrm{mM} \mathrm{NaCl}$ was added in one step. Tube 3: $100 \mathrm{nM}$ DNA, but $\mathrm{NaCl}$ was added in 30 $\mathrm{mM}, 60 \mathrm{mM}$, and $60 \mathrm{mM}$ increments (final $150 \mathrm{mM} \mathrm{NaCl}$ ). (F) Effect of DNA length; all samples contained $120 \mathrm{mM} \mathrm{NaCl}$. Tube 1: no DNA. Tube 2: 12-mer DNA, Tube 3: 70-mer DNA.

AuNPs incubated with DNA of different lengths were also analyzed using gel electrophoresis. After running for a few minutes, most of the AuNPs remained red and the sample incubated with longer DNAs migrated faster (Figure 3C), suggesting the presence of more negative charges on the AuNPs. After the 12-mer DNA protected AuNPs stopped moving, the 70-mer protected ones were still migrating (Figure 3D), suggesting that the longer DNAs were adsorbed with a higher stability and better at protecting AuNPs from aggregation. To further verify this, AuNPs were incubated with the 
12-mer and 70-mer DNA respectively. After adding $120 \mathrm{mM} \mathrm{NaCl}$, the 12-mer sample changed color to purple (Figure 3F, tube 2) but not the 70-mer one (tube 3), confirming that longer DNAs were more effective for protection, as long as they were adsorbed. It has been well established that shorter DNAs were able to bind to AuNPs faster than longer DNAs. ${ }^{23}$ We show here that once adsorbed, longer DNAs bind to AuNPs much more strongly and are better at protecting AuNPs, which is attributed to longer DNAs being able to establish more binding sites on AuNP surface.$^{57}$ For analytical applications, it is therefore important to realize that the preferential adsorption of short DNA is a kinetic phenomenon.

DNA adsorption isotherm. Adsorption isotherm is a useful tool in surface science since it provides information on not only adsorption but also desorption. Our gel electrophoresis experiments suggest that adsorbed DNA could desorb. To further understand the interaction between DNA and AuNPs, adsorption isotherms were measured after overnight incubation of $2 \mathrm{nM}$ AuNPs mixed with varying concentrations of FAM-labeled DNA. As shown in Figure 4A, Langmuir isotherms were observed in both high and low salt conditions for the 12-mer DNA. By fitting the data to the Langmuir isotherm $\square \square a K C /(1 \square K C)$, where $K$ is the Langmuir constant, $a$ is the adsorption capacity, $C$ is the DNA concentration, and $\square$ is the adsorbed DNA, we determined that $K=0.022 \square 0.004 \mathrm{nM}^{-1}$ for the $60 \mathrm{mM}$ $\mathrm{NaCl}$ sample and $K=0.015 \square 0.004$ in the absence of $\mathrm{NaCl}$ (i.e. less than one-fold difference). These Langmuir isotherms indicate the presence of both adsorption and desorption. The adsorption is very slow in the absence of salt (Figure 1A). Therefore, the rate of desorption must also be slow in the absence of salt to reach a Langmuir constant comparable to that in $60 \mathrm{mM} \mathrm{NaCl}$. To confirm this, we carried out a desorption experiment with pre-adsorbed DNA. As shown in Figure 4C, the desorption rate was indeed slower in the presence of lower $\mathrm{NaCl}$. We propose that DNA displaces citrate on AuNP upon adsorption and thereafter the electrostatic repulsion between AuNP and adsorbed DNA is minimal. In a low salt buffer, it may be more favourable for DNA to adapt an extended conformation on AuNP 
to reduce intramolecular electrostatic repulsion, which helps expose DNA bases to AuNP surface and strengthen the binding. With high salt, the DNA internal charges are screened to allow for more compact structures on the AuNP surface, reducing the number of contacting points and facilitating desorption.
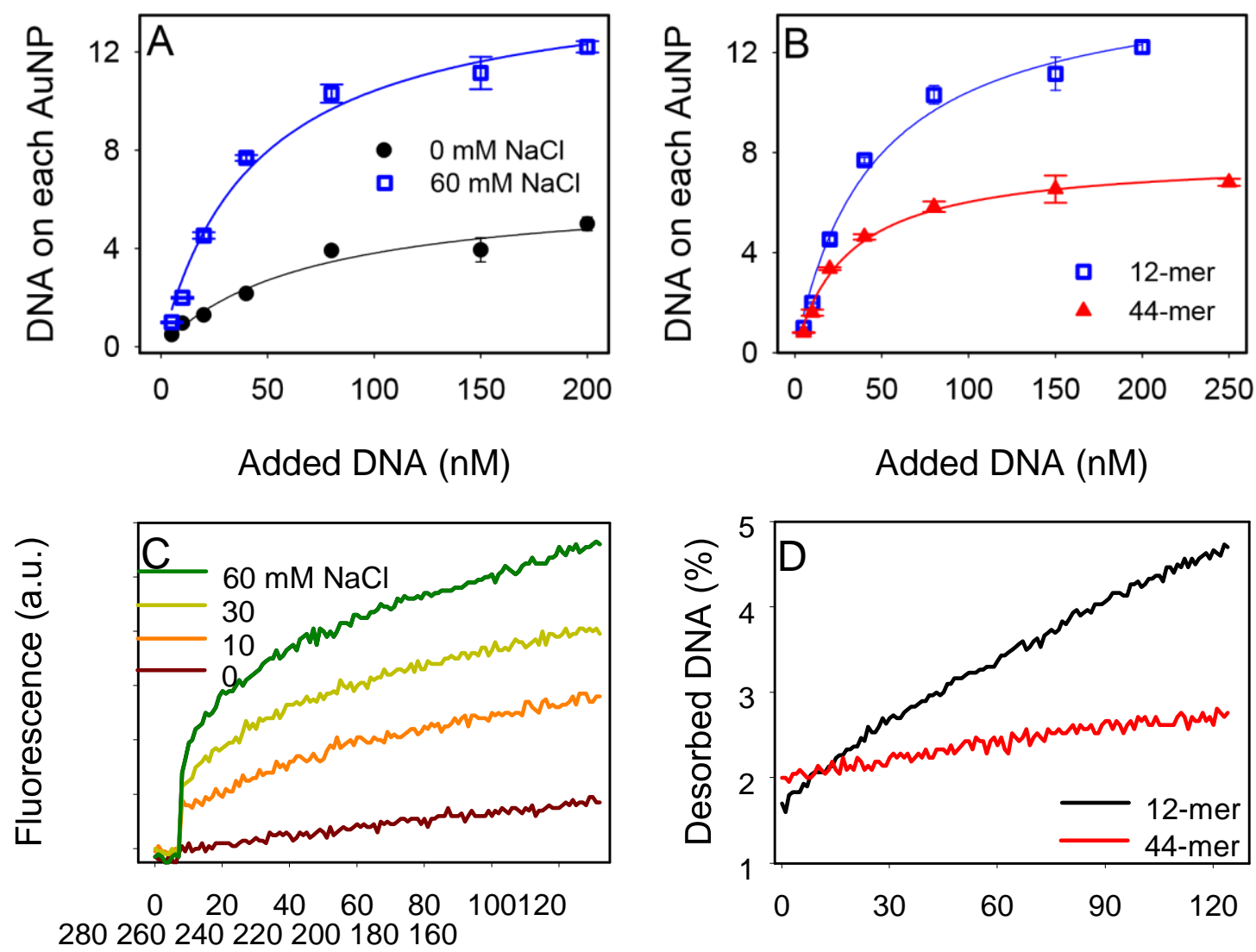

Time $(\min )$ Time (min)

Figure 4. DNA adsorption isotherm as a function of salt (A) and DNA length (B). (C) DNA desorption kinetics in the presence of various $\mathrm{NaCl}$ concentrations for the 44-mer $\mathrm{DNA}$, where $\mathrm{NaCl}$ was added at 5 min to induce desorption. (D) Desorption kinetics for the 12- and 44-mer DNA in $30 \mathrm{mM} \mathrm{NaCl}$. No AuNP aggregation was observed for the desorption experiment. 
We next compared the adsorption isotherms of the 12 and 44-mer DNAs, whose Langmuir constants were $0.022 \square 0.004 \mathrm{nM}^{-1}$ and $0.033 \square 0.004 \mathrm{nM}^{-1}$, respectively (Figure 4B). The physical meaning of Langmuir constant is the ratio of the rate constant of adsorption over desorption. Therefore, the larger Langmuir constant for the longer DNA indicates that its adsorption is relatively more favourable. Since the rate of adsorption is faster for the 12-mer DNA than 44-mers (see Supporting Information), the rate of desorption must be slower for the 44-mer. This has also been confirmed by the desorption experiment (Figure 4D) and the gel electrophoresis studies. Note that in Figure 4D the rate of desorption is extremely slow and only $\sim 0.5 \%$ of the 44 -mer DNA was desorbed in $2 \mathrm{hrs}$.

Effect of pH. The above studies show the critical role of salt in determining DNA adsorption kinetics and capacity. The main effect of salt is to screen the negative charges. Since the negative charges on AuNP surface are believed to be from the adsorbed citrate, lowering the buffer $\mathrm{pH}$ should lead to citrate protonation and thus facilitate DNA adsorption. To test this, we mixed $100 \mathrm{nM}$ of the 12-mer DNA with $5 \mathrm{nM}$ AuNPs (ratio $=20: 1$ ) at various $\mathrm{pH}$. Since FAM is a $\mathrm{pH}$ sensitive fluorophore, the adsorbed DNA was desorbed by BME and then quantified by measuring fluorescence in $50 \mathrm{mM}$ pH 7.6 HEPES buffer. As shown in Figure 5, $\sim 90 \%$ adsorption was achieved at $\mathrm{pH} 3.5$ and the amount of adsorption progressively decreased as the solution $\mathrm{pH}$ increased. There are three carboxyl groups on a citrate and the $\mathrm{pK}_{\mathrm{a}}$ values are 3.1, 4.8, and 6.4, respectively. We tested a $\mathrm{pH}$ range covering two of the $\mathrm{pK}_{\mathrm{a}}$ 's, leading to more than 5-fold change in the amount of adsorbed DNA. This experiment further supported the role of surface citrate in creating the electrostatic barrier. 


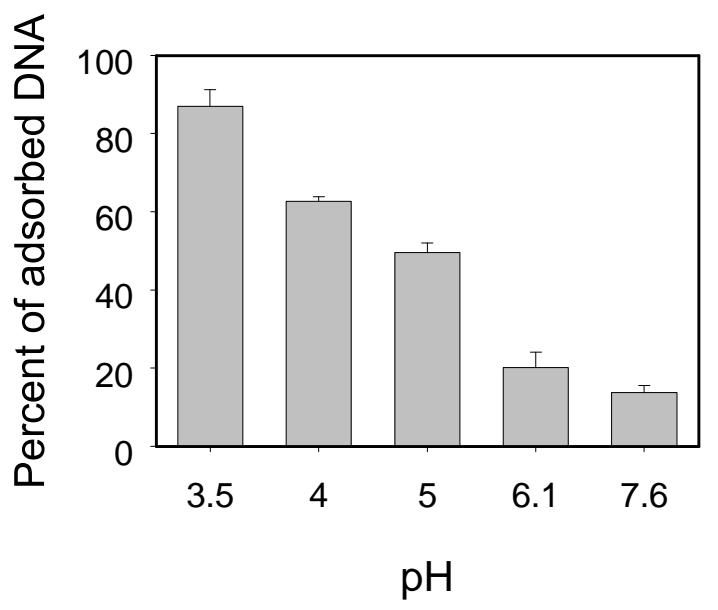

Figure 5. Percentage of adsorbed DNA as a function of $\mathrm{pH}$. AuNP concentration was $5 \mathrm{nM}$ and the 12mer DNA was $100 \mathrm{nM}$.

Effect of solvent polarity. Based on studying DNA adsorption kinetics in the presence of different types of salts, Rothberg suggested that AuNP surface was hydrophobic and the main interaction between AuNP and DNA was hydrophobic interaction. ${ }^{41}$ There was a controversy regarding the hydrophobicity of gold. Depending on the protocol to prepare and clean gold surfaces, different results were obtained. In the early 1980s, the experiments involved planar gold surfaces concluded that gold is hydrophilic as long as its surface is clean. ${ }^{58,59}$ In other words, hydrophobicity can only be introduced through adsorbed organic contaminants. In our experiment, the as-prepared citrate capped AuNPs could be easily dispersed in water, which is a strong indication of surface hydrophilicity. On the contrary, when AuNP capped with hydrophobic alkylthiol chains, they cannot be dispersed in water. ${ }^{7}$

In addition, hydrophobic interaction should be reduced by using a less polar solvent. For example, addition of methanol reduces the binding between DNA and a hydrophobic $\mathrm{C}_{18}$ surface. ${ }^{60} \mathrm{We}$ measured the adsorption of the 12-mer DNA in various percentages of ethanol. In the absence of $\mathrm{NaCl}$, little adsorption occurred if ethanol was less than 50\% (Figure 6A). Interestingly, 80\% or higher ethanol induced close to complete DNA adsorption. Similar observations were also achieved using isopropanol 
(see Supporting Information). The AuNPs were aggregated in the presence of ethanol. ${ }^{20}$ DNA quantification was made after centrifugation and measurement of the supernatant fluorescence. Control experiments (e.g. no AuNPs) showed no DNA adsorption onto the container surface (the microcentrifuge tubes), indicating that the measured DNA was associated with AuNPs. Ionization in ethanol is expected to be disfavored and the surface charge on AuNP is also reduced, enhancing DNA adsorption. DNA is also known to undergo conformational changes in high ethanol solution. For example, the B to A DNA form transition happens in the presence of $70-80 \%$ ethanol. ${ }^{61}$ It is unclear whether this can also contribute to the observed higher adsorption of ss-DNA to AuNPs in the presence of high concentrations of ethanol.
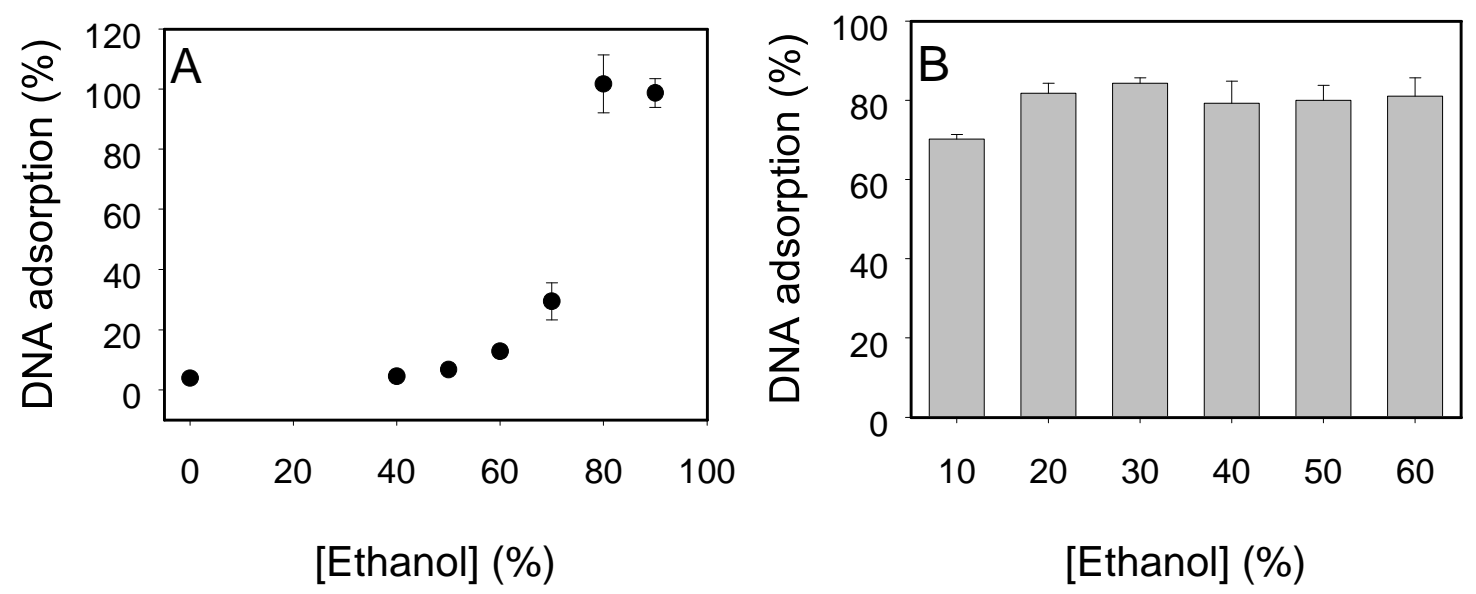

Figure 6. (A) Percentage of adsorbed DNA as a function of ethanol in the absence of $\mathrm{NaCl}$. (A) 0.75 nM AuNPs mixed with $20 \mathrm{nM}$ 12-mer DNA in solution containing various concentration of ethanol prior to a 2-min incubation. (B) DNA mixed with AuNPs in 80\% ethanol for $1 \mathrm{~h}$ to achieve complete adsorption followed by diluting ethanol to the desired concentration. 
To test if the observed ethanol effect was just a kinetic phenomenon, we modified the procedure by first incubating the DNA in $80 \%$ ethanol to achieve high adsorption. Following that, water was added to dilute the samples to lower ethanol concentrations and the amount of DNA remained on AuNP surface was measured after $2 \mathrm{hr}$ incubation. As shown in Figure 6C, all the samples maintained a high percentage of DNA. This experiment also indicated that the high DNA adsorption in concentrated ethanol was not due to DNA aggregation. Otherwise, reduced adsorption should be observed after diluting ethanol. This study did not support that ethanol could weaken the binding between DNA and AuNPs. Therefore, we conclude that while the interaction between DNA bases and AuNPs is the main stabilizing force, its nature is not hydrophobic interaction but related to specific chemical interactions, such as through the N3 and N7 sites on adenine and guanine bases, which is supported by various

spectroscopy and theoretic studies. ${ }^{42,46-49}$

Binding model. Based on this work, we propose that electrostatic interaction not only determines adsorption kinetics, but also influences binding capacity and desorption. Non-electrostatic attractive forces are responsible for adsorption. We suggest the following model to describe the DNA adsorption. First, negatively charged DNA displaces surface citrate upon DNA adsorption (Figure 7A). This process requires the DNA to first approach the AuNP surface, which can be facilitated by a high salt concentration, low $\mathrm{pH}$, or a high concentration of ethanol. Once adsorbed, the DNA may change conformation on the surface to maximize its surface contact. Adsorbed DNAs create an exclusion zone to other incoming DNAs based not only on their physical sizes (e.g. hydrodynamic radius defined by the blue circles in Figure 7) but also on their electric potentials (e.g. the radius defined by the red circles). Once the electrostatic exclusion zones start to overlap, further adsorption of more DNAs is disfavored. The size of these exclusion zones is a function of salt concentration, as higher salt tends to screen the charge more completely and make DNA more compact. Meanwhile, salt-induced DNA compaction 
reduces the number of contacting points with the AuNP surface and favors desorption. Therefore, salt increases the rate of both adsorption and desorption. Longer DNAs occupy more surface area because of their larger hydrodynamic size and high charge (Figure 7B).
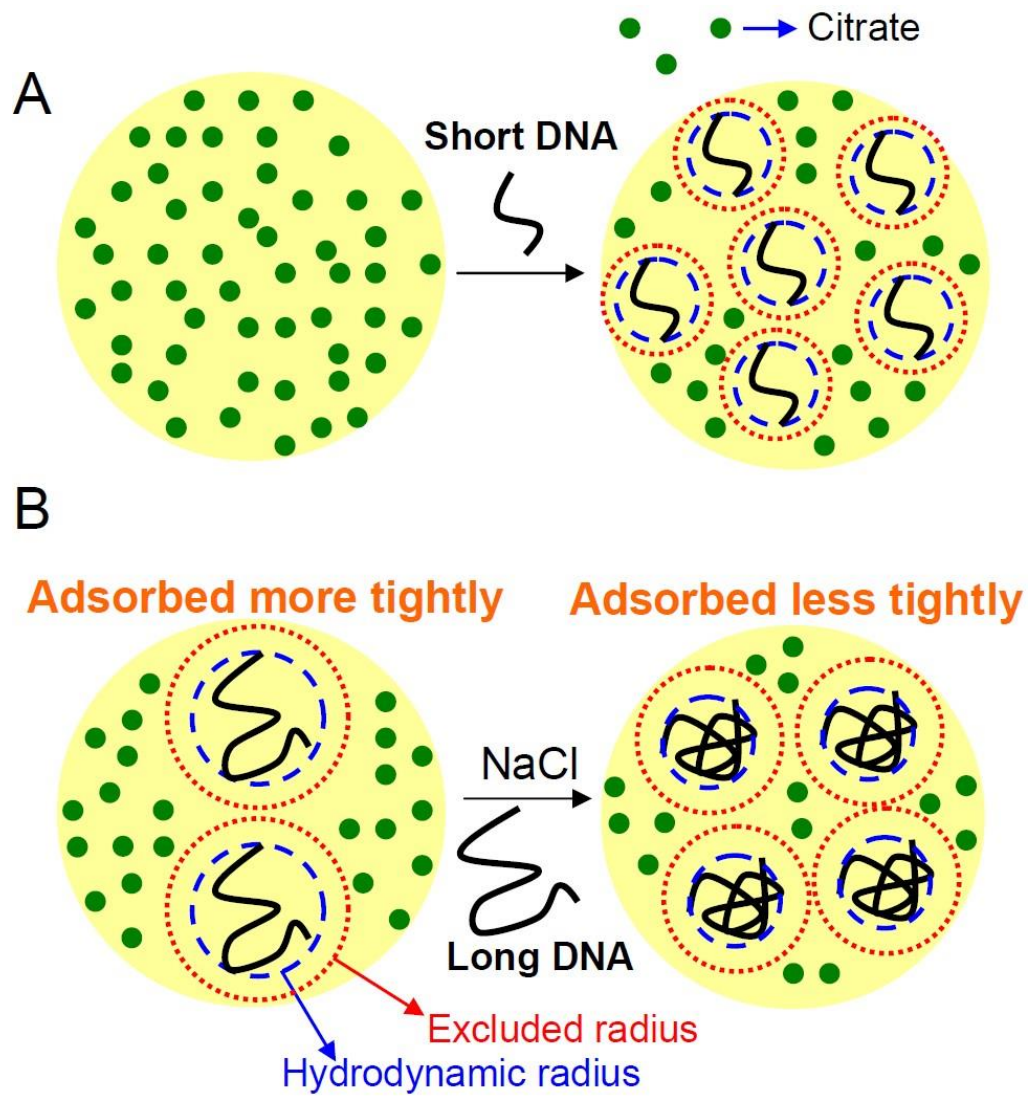

Figure 7. (A) Schematics showing DNA adsorption through displacement of citrate on AuNP surface. Each DNA is represented by its hydrodynamic size (the blue rings) as well as its electrostatically excluded area to other DNAs (the red rings) because of its negative charges. Once the red rings approach to overlapping, further DNA adsorption is disfavoured. (B) The excluded area for longer DNAs is larger to give rise to lower binding capacity. In the presence of more salt, the capacity can increase because of charge screening and DNA compaction, but the same process also makes the DNA adsorb less tightly and desorb more easily. 
To test this model, we re-plotted Figure $2 \mathrm{~A}$ to correlate Debye length $\left(\lambda_{D}\right)$ with the DNA excluded radius. Since the average radius of each AuNP is $6.5 \mathrm{~nm}$, its surface area is $531 \mathrm{~nm}^{2}$. The exclusion radius is calculated by dividing this surface area by the number of adsorbed DNA. As shown in Figure 2B, linear relationships are obtained by plotting the DNA excluded radius against $\square_{D}$, which supports that $\lambda_{D}$ affected the adsorption capacity. We noticed that the slopes of the lines are different. For example, the 44-mer DNA has a slope of 1.74 while the 12 -mer DNA has a slope of only 0.36 . This means that reducing $\square_{D}$ by $1 \mathrm{~nm}$ can reduce the excluded radius by $1.74 \mathrm{~nm}$ for the $44-$ mer DNA but only $0.36 \mathrm{~nm}$ for the 12 -mer. We reason that this difference is related to the absolute number of charges on each DNA. The 44-mer DNA carries 43 negative charges and the 12-mer carries only $11 . \lambda_{D}$ only defines the relative electrostatic potential decay pattern, while DNA interaction on AuNP surface is more affected by the absolute repulsive force. Since the 44-mer has more charges, its absolute electrostatic force, which is directly related to the excluded radius, is more affected by salt concentration or $\lambda_{D}$.

\section{Conclusions.}

In this work, we systematically studied the adsorption of DNA to AuNPs as a function of salt concentration, $\mathrm{pH}$, solvent composition, and DNA oligomer length. Quantitative measurements of adsorption isotherms and desorption were also carried out to resolve several controversies in this field. For example, we demonstrate that adsorbed DNA can desorb. Interestingly, adding salt increased both adsorption rate and desorption rate of DNA from AuNPs. We also demonstrate that longer DNA 
oligomers are much more effective in protecting AuNPs, although shorter DNAs are adsorbed with faster kinetics. Finally, our data do not support hydrophobic force to be the main contributor for DNA adsorption. Based on previous spectroscopic and theoretic work, we concur that specific chemical interactions between DNA bases and AuNP surface are the main stabilizing force.

\section{Acknowledgements}

Funding for this work is from the University of Waterloo, the Canadian Foundation for Innovation, Ontario Ministry of Research \& Innovation, the Ontario Early Researcher Award, Canadian Institutes of Health Research, and the Discovery Grant of the Natural Sciences and Engineering Research Council (NSERC) of Canada.

Supporting Information Available. DNA length dependent adsorption kinetics, DNA adsorption in isopropanol and kinetic data normalization. This material is available free of charge via the Internet at http://www.acs.org.

\section{References:}

(1) Rosi, N. L.; Mirkin, C. A. Chem. Rev. 2005, 105, 1547-1562.

(2) Giljohann, D. A.; Seferos, D. S.; Daniel, W. L.; Massich, M. D.; Patel, P. C.; Mirkin, C. A. Angew. Chem. Int. Ed. 2010, 49, 3280-3294.

(3) Katz, E.; Willner, I. Angew. Chem., Int. Ed. 2004, 43, 6042-6108.

(4) Zhao, W.; Brook, M. A.; Li, Y. Chembiochem 2008, 9, 2363-2371.

(5) Wang, H.; Yang, R. H.; Yang, L.; Tan, W. H. ACS Nano 2009, 3, 2451-2460.

(6) Liu, J.; Cao, Z.; Lu, Y. Chem. Rev. 2009, 109, 1948-1998. 
(7) Daniel, M.-C.; Astruc, D. Chem. Rev. 2004, 104, 293-346.

(8) Mirkin, C. A.; Letsinger, R. L.; Mucic, R. C.; Storhoff, J. J. Nature 1996, 382, 607-609.

(9) Alivisatos, A. P.; Johnsson, K. P.; Peng, X.; Wilson, T. E.; Loweth, C. J.; Bruchez, M. P., Jr;

Schultz, P. G. Nature 1996, 382, 609-611.

(10) Chen, W.; Bian, A.; Agarwal, A.; Liu, L.; Shen, H.; Wang, L.; Xu, C.; Kotov, N. A. Nano Lett. 2009, 9, 2153-2159.

(11) Sharma, J.; Chhabra, R.; Cheng, A.; Brownell, J.; Liu, Y.; Yan, H., Science 2009, 323, 112-116.

(12) Lin, C.; Liu, Y.; Yan, H. Biochemistry 2009, 48, 1663-1674.

(13) Park, S. Y.; Lytton-Jean, A. K. R.; Lee, B.; Weigand, S.; Schatz, G. C.; Mirkin, C. A. Nature 2008, 451, 553-556.

(14) Nykypanchuk, D.; Maye, M. M.; van der Lelie, D.; Gang, O. Nature 2008, 451, 549-552.

(15) Macfarlane, R. J.; Lee, B.; Jones, M. R.; Harris, N.; Schatz, G. C.; Mirkin, C. A. Science 2011, 334, 204-208.

(16) Jin, R.; Wu, G.; Li, Z.; Mirkin, C. A.; Schatz, G. C. J. Am. Chem. Soc. 2003, 125, 1643-1654.

(17) Lytton-Jean, A. K. R.; Mirkin, C. A. J. Am. Chem. Soc. 2005, 127, 12754-12755.

(18) Harris, N. C.; Kiang, C. H. J. Phys. Chem. B 2006, 110, 16393-16396.

(19) Smith, B. D.; Dave, N.; Huang, P.-J. J.; Liu, J. J. Phys. Chem. C 2011, 115, 7851-7857.

(20) Smith, B. D.; Liu, J. J. Am. Chem. Soc. 2010, 132, 6300-6301.

(21) Bhatt, N.; Huang, P.-J. J.; Dave, N.; Liu, J. Langmuir 2011, 27, 6132-6137.

(22) Li, H.; Rothberg, L. J. Anal. Chem. 2004, 76, 5414-5417.

(23) Li, H.; Rothberg, L. J. J. Am. Chem. Soc. 2004, 126, 10958-10961.

(24) Li, H.; Rothberg, L. Proc. Natl. Acad. Sci. U.S.A. 2004, 101, 14036-14039.

(25) Li, H.; Liang, R.; Turner, D. H.; Rothberg, L. J.; Duan, S. RNA 2007, 13, 2034-2041. 
(26) Zhang, J.; Wang, L. H.; Pan, D.; Song, S. P.; Boey, F. Y. C.; Zhang, H.; Fan, C. H. Small 2008, 4, 1196-1200.

(27) Lee, J. H.; Wang, Z.; Liu, J.; Lu, Y. J. Am. Chem. Soc. 2008, 130, 14217-14226.

(28) Wang, W.; Chen, C.; Qian, M.; Zhao, X. S. Anal. Biochem. 2008, 373, 213-219.

(29) Wang, Z.; Lee, J. H.; Lu, Y. Adv. Mater. 2008, 3263-3267.

(30) Wei, H.; Li, B.; Li, J.; Dong, S.; Wang, E. Nanotechnology 2008, 19, 095501.

(31) Wang, L.; Liu, X.; Hu, X.; Song, S.; Fan, C. Chem. Comm. 2006, 3780-3782.

(32) Wang, J.; Wang, L. H.; Liu, X. F.; Liang, Z. Q.; Song, S. P.; Li, W. X.; Li, G. X.; Fan, C. H. Adv. Mater. 2007, 19, 3943-3946.

(33) Wang, Z.; Zhang, J.; Ekman, J. M.; Kenis, P. J. A.; Lu, Y. Nano Lett. 2010, 10, 1886-1891.

(34) Xu, L.; Zhu, Y.; Ma, W.; Chen, W.; Liu, L.; Kuang, H.; Wang, L.; Xu, C. J. Phys. Chem. C 2011, 115, 3243-3249.

(35) Zheng, X.; Liu, Q.; Jing, C.; Li, Y.; Li, D.; Luo, W.; Wen, Y.; He, Y.; Huang, Q.; Long, Y.-T.; Fan, C. Angew. Chem., Int. Ed. 2011, 50, 11994-11998.

(36) Park, K. S.; Kim, M. I.; Cho, D.-Y.; Park, H. G. Small 2011, 7, 1521-1525.

(37) Li, H. K.; Huang, J. H.; Lv, J. H.; An, H. J.; Zhang, X. D.; Zhang, Z. Z.; Fan, C. H.; Hu, J. Angew. Chem. Int. Ed. 2005, 44, 5100-5103.

(38) Rosi, N. L.; Giljohann, D. A.; Thaxton, C. S.; Lytton-Jean, A. K. R.; Han, M. S.; Mirkin, C. A. Science 2006, 312, 1027-1030.

(39) Ostblom, M.; Liedberg, B.; Demers, L. M.; Mirkin, C. A. J. Phys. Chem. B 2005, 109, 1515015160.

(40) Storhoff, J. J.; Elghanian, R.; Mirkin, C. A.; Letsinger, R. L. Langmuir 2002, 18, 6666-6670.

(41) Nelson, E. M.; Rothberg, L. J. Langmuir 2011, 27, 1770-1777. 
(42) Gourishankar, A.; Shukla, S.; Ganesh, K. N.; Sastry, M. J. Am. Chem. Soc. 2004, 126, 1318613187.

(43) Wolf, L. K.; Gao, Y.; Georgiadis, R. M. Langmuir 2004, 20, 3357-3361.

(44) Dhumale, V. A.; Shah, P. V.; Mulla, I. S.; Sharma, R. B. Appl. Surf. Sci. 2010, 256, 4192-4195.

(45) Tian, J.; Zheng, F.; Zhao, H. Y. J. Phys. Chem. C 2011, 115, 3304-3312.

(46) Jang, N. H. B. Korean Chem. Soc. 2002, 23, 1790-1800.

(47) Pong, B.-K.; Lee, J.-Y.; Trout, B. L. Langmuir 2005, 21, 11599-11603.

(48) Kumar, A.; Mishra, P. C.; Suhai, S. J. Phys. Chem. A 2006, 110, 7719-7727.

(49) Plekan, O.; Feyer, V.; Ptasinska, S.; Tsud, N.; Chab, V.; Matolin, V.; Prince, K. C. J. Phys.

Chem. C 2010, 114, 15036-15041.

(50) Zuker, M. Nucleic Acids Res. 2003, 31, 3406-3415.

(51) Storhoff, J. J.; Elghanian, R.; Mucic, R. C.; Mirkin, C. A.; Letsinger, R. L. J. Am. Chem. Soc. 1998, 120, 1959-1964.

(52) Su, X. D.; Kanjanawarut, R. ACS Nano 2009, 3, 2751-2759.

(53) Demers, L. M.; Mirkin, C. A.; Mucic, R. C.; Reynolds, R. A., III; Letsinger, R. L.; Elghanian, R.; Viswanadham, G. Anal. Chem. 2000, 72, 5535-5541.

(54) Hill, H. D.; Millstone, J. E.; Banholzer, M. J.; Mirkin, C. A. ACS Nano 2009, 3, 418-424.

(55) Hurst, S. J.; Lytton-Jean, A. K. R.; Mirkin, C. A. Anal. Chem. 2006, 78, 8313-8318.

(56) Parak, W. J.; Pellegrino, T.; Micheel, C. M.; Gerion, D.; Williams, S. C.; Alivisatos, A. P. Nano Lett. 2003, 3, 33-36.

(57) Steel, A. B.; Levicky, R. L.; Herne, T. M.; Tarlov, M. J. Biophys. J. 2000, 79, 975-981.

(58) Gardner, J. R.; Woods, R. J. Electroanal. Chem. Interfacial Electrochem. 1977, 81, 285-290. 
(59) Tennyson, S. J. Colloid Interf. Sci. 1980, 75, 51-55.

(60) Kang, S. H.; Shortreed, M. R.; Yeung, E. S. Anal. Chem. 2001, 73, 1091-1099.

(61) Piskur, J.; Rupprecht, A. FEBS Letters 1995, 375, 174-178. 
